\title{
An uncommon etiology of pancreatitis after endoscopic ultrasound-guided fine needle aspiration
}
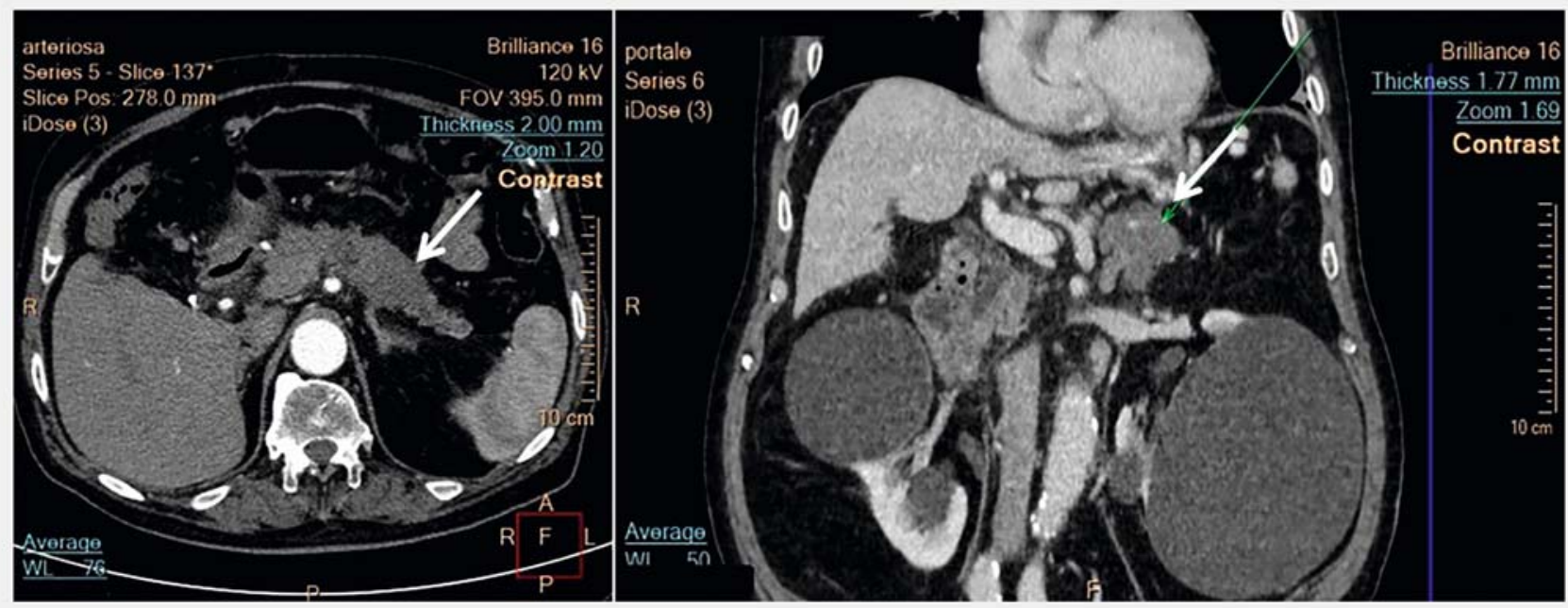

- Fig. 1 Computed tomography scan images showing the pancreatic mass at the body-tail border (arrow).

An 82-year-old man was referred to our unit with a pancreatic mass. A computed tomography scan had demonstrated a 6 -cm solid lesion in the body-tail region of the pancreas, with local lymph node involvement, highly suggestive of malignancy ( Fig.1). Endoscopic ultrasound (EUS) was then performed (Olympus GF-UCT 180; Olympus Medical, Tokyo, Japan). The solid mass, located at the distal pancreatic body ( $>$ Fig. 2 ) showed irregular margins and splenic vein infiltration. Fine needle aspiration (FNA) using a 19-gauge needle (Olympus EZ Shot 3 plus) was performed for four passes, with a final histopathological diagnosis of "mucinous adenocarcinoma." No immediate complications were observed following the procedure, but the patient was kept fasted. The following day, after refeeding, he complained of severe abdominal pain and coffee-ground emesis. Laboratory analysis showed an increase in amylase and lipase levels (about 3-4 times upper limit of normal), without a fall in hemoglobin. Therefore, upper gastrointestinal endoscopy was performed and duodenoscopy demonstrated a clot adherent to the major papilla
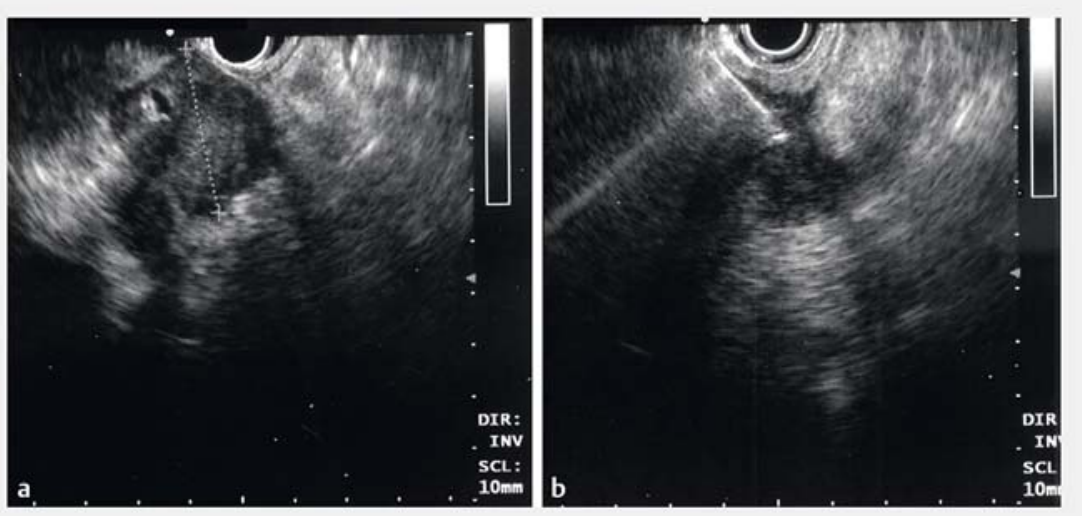

- Fig. 2 Endoscopy ultrasound scan images before and during biopsy of the mass in the distal pancreatic body.

( Video 1). Extraction by forceps was attempted and revealed a long sausage-like brown clot that seemed to be molded to the shape of the pancreatic duct. Thereafter, the patient's pain and laboratory abnormalities promptly disappeared.

Pancreatitis and bleeding may be complications of pancreatic EUS-FNA [1], although blood loss in the pancreatic duct, known as "hemosuccus pancreaticus," is very rare; to the best of our knowledge, only four cases have been described as post-procedural complications [2-5]. The peculiarity of our experience was the absence of active bleeding and the presence of a clot molded to the shape of the main pancreatic duct. Presumably, this event had led to pancreatic duct obstruction that, in turn, was the trigger for an episode of acute pancreatitis. Resolution of the pancreatitis after clot removal strongly supports our hypothesis. 


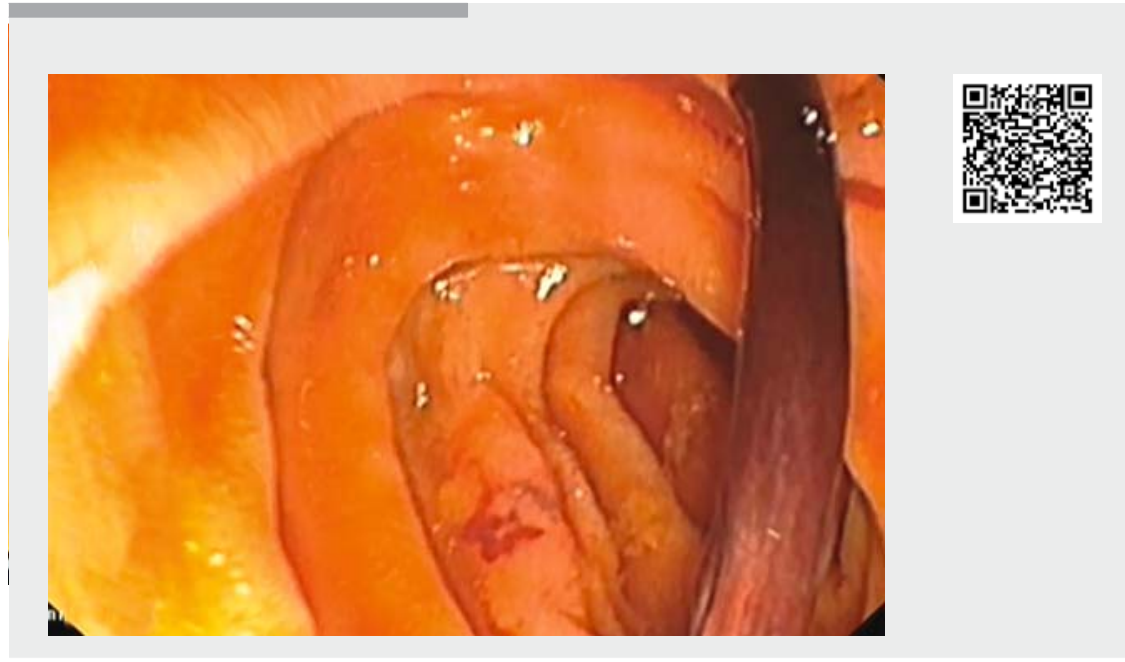

$\checkmark$ Video 1 Extraction of the clot from the major papilla using forceps during duodenoscopy.

Endoscopy_UCTN_Code_CCL_1AB_2AF

Acknowledgments

We thank Prof. Enzo lerardi for critical revision of the manuscript and Dr. Giuseppe Casucci for video editing.

\section{Competing interests}

None

\section{The authors}

Osvaldo Burattini ${ }^{1,{ }^{*}}$, Giuseppe Losurdo ${ }^{2,}$, Stefania Marangi ${ }^{1}$, Margherita Curlo', Mauro Mastronardi ${ }^{1}$, Pietro Giorgio ${ }^{1}$, Antonio Pisani ${ }^{1}$

1 Section of Gastroenterology II, National Institute of Research "Saverio De Bellis", Castellana Grotte, Italy

2 Section of Gastroenterology, Department of Emergency and Organ Transplantation,

University of Bari, Bari, Italy

\section{Corresponding author}

\section{Osvaldo Burattini, MD}

Section of Gastroenterology II, National Institute of Research "Saverio De Bellis", Via Turi 27, 70013 Castellana Grotte, Italy Fax: +39-080-4994250 osvaldoburattini73@gmail.com

\section{References}

[1] Al-Haddad M, Wallace MB, Woodward TA et al. The safety of fine-needle aspiration guided by endoscopic ultrasound: a prospective study. Endoscopy 2008; 40: 204 208

[2] Singh P, Gelrud A, Schmulewitz N et al. Hemosuccus pancreaticus after EUS-FNA of pancreatic cyst (with video). Gastrointest Endosc 2008; 67: 543

[3] Keswani RN. Hemosuccus pancreaticus after endoscopic ultrasound-guided fine needle aspiration of a pancreatic cyst. Endoscopy 2010; 42 (Suppl. 02): E79
[4] Cheruvattath R, Diehl DL. Hemosuccus pancreaticus after EUS-FNA of a pancreatic tail cyst. Gastrointest Endosc 2009; 70: 817

[5] Barresi L, Tarantino I, Ligresti D et al. Fully covered self-expandable metal stent treatment of spurting bleeding into the biliary tract after endoscopic ultrasound-guided fine-needle aspiration of a solid lesion of the pancreatic head. Endoscopy 2015; 47 (Suppl. 01): E87-E88

\section{Bibliography}

DOI https://doi.org/10.1055/a-1011-3796

Published online: 11.10.2019

Endoscopy 2020; 52: E106-E107

(c) Georg Thieme Verlag KG

Stuttgart · New York

ISSN 0013-726X

\section{ENDOSCOPY E-VIDEOS \\ https://eref.thieme.de/e-videos}

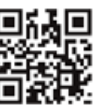

Endoscopy E-Videos is a free access online section, reporting on interesting cases and new

techniques in gastroenterological endoscopy. All papers include a high quality video and all contributions are freely accessible online.

This section has its own submission website at https://mc.manuscriptcentral.com/e-videos

\footnotetext{
* Equal first authors
} 